\title{
A Recombinant Adenovirus Encoding Multiple HIV-1 Epitopes Induces Stronger CD4+ T cell Responses than a DNA Vaccine in Mice
}

Daniela Santoro Rosa ${ }^{1,2,4}$, Susan Pereira Ribeiro ${ }^{1,2}$, Rafael Ribeiro Almeida ${ }^{1}$, Eliane Conti Mairena ${ }^{2,3}$, Jorge Kali1 ${ }^{1,2,3}$ and Edecio CunhaNeto ${ }^{1,2,3 *}$

${ }^{1}$ Laboratory of Clinical Immunology and Allergy-LIM60, Division of Clinical Immunology and Allergy, Department of Medicine, Brazil

${ }^{2}$ Institute for Investigation in Immunology-INCT, Sao Paulo, Brazil

${ }^{3}$ Heart Institute (InCor), University of Sao Paulo School of Medicine, Sao Paulo, Brazil

${ }^{4}$ Division of Immunology-Federal University of Sao Paulo-UNIFESP, Sao Paulo, Brazil

\begin{abstract}
T-cell based vaccines against SIV/HIV may reduce both transmission and disease progression by inducing broad and functionally relevant $\mathrm{T}$ cell responses. Mounting evidence points toward a critical role for $\mathrm{CD} 4^{+} \mathrm{T}$ cells in the control of immunodeficiency and virus replication. We have previously shown that a DNA vaccine $(\mathrm{HIVBr} 18)$, encoding 18 HIV CD4 epitopes capable of binding to multiple HLA class II molecules was able to elicit broad, polyfunctional, and long-lived $\mathrm{CD} 4^{+}$and $\mathrm{CD} 8^{+} \mathrm{T}$ cell responses in BALB/C and multiple HLA class II transgenic mice. By virtue of inducing broad responses against conserved $C D 4^{+} \mathrm{T}$ cell epitopes that could be recognized across diverse common HLA class II alleles, this vaccine concept may cope with HIV-1 genetic variability and increase population coverage. Given the low immunogenicity of DNA vaccines in clinical trials, we tested the ability of a recombinant adenovirus serotype 5 encoding the $18 \mathrm{HIV}$ epitopes (Ad5-HIVBr18) to increase specific cellular immune responses. We assessed the breadth and magnitude of HIV-specific proliferative and cytokine responses of $\mathrm{CD}^{+}$and $\mathrm{CD}^{+} \mathrm{T}$ cells induced by $\mathrm{Ad} 5-\mathrm{HIVBr} 18$ using different vaccination regimens/routes and compared to DNA immunization. Immunization with Ad5-HIVBr18 induced significantly higher specific $\mathrm{CD}_{4}^{+}$and $\mathrm{CD}^{+} \mathrm{T}$ cell proliferation, IFN- $\gamma$ and TNF- $\alpha$ production than HIVBr18. The subcutaneous route of Ad5-HIVBr18 administration was associated with the highest responses. Ad5-HIVBr18 induced higher proliferative and cytokine responses than HIVBr18 up to 28 weeks post-immunization. Our results indicate that a vaccine based on an adenovirus vector encoding the HIVBr18 epitopes shows superior immunogenicity as compared to its DNA counterpart. These results support the possible testing of a vaccine encoding HIVBr18 in non-human primates and future clinical trials.
\end{abstract}

Keywords: HIV vaccine; $\mathrm{CD}^{+} \mathrm{T}$ cells; Epitopes; Adenovirus; Polyfunctional; HIV-1; Vaccine

Abbreviations: Ad5: Replication-Defective Recombinant Adenovirus Serotype 5; Ad5- $\beta$ gal: Replication-Defective Recombinant Adenovirus Serotype 5 Encoding $\beta$-Galactosidase; PBMC: Peripheral Blood Mononuclear Cells; CFSE: Carboxyfluorescein Succinimidyl Ester; CTL: Cytotoxic CD8 ${ }^{+}$T lymphocyte; HIV: Human Immunodeficiency Virus; SIV: Simian Immunodeficiency Virus; IM: Intramuscular; SC: Subcutaneous; SFU: Spot Forming Units; CMI: Cell Mediated Immune Responses

\section{Introduction}

Despite significant advances in therapy, the AIDS pandemic is responsible for devastating morbidity and mortality throughout the world (http://www.who.int/hiv/data/en/index.html), especially in regions with limited access to antiretroviral drugs. Vaccine strategies targeting the induction of neutralizing antibodies against HIV-1 have failed to provide protection $[1,3]$. Alternative approaches have focused on vaccines that stimulate cell-mediated immune responses (CMI) against conserved HIV-1 proteins in an attempt to attenuate infection $[4,5]$. Two vaccine concepts that have recently completed clinical efficacy studies also evaluated the induction of CMI responses. The STEP trial showed negative results [5], while the RV144, which also aimed at inducing protective antibodies, presented borderline efficacy [6].

Immunological analysis from the RV 144 study showed that the vaccine-induced immune response was essentially composed of $\mathrm{CD}^{+} \mathrm{T}$ cells and binding antibodies [6], suggesting that $\mathrm{CD} 4^{+} \mathrm{T}$ cells could play an important role in HIV vaccine-induced immunity.
Furthermore, vaccination strategies that induced SIV-specific CD4 $4^{+}$ along with $\mathrm{CD}^{+}-\mathrm{T}$ cell responses were able to lower viral load after heterologous challenge $[7,8]$.

Searching for new HIV vaccine concept, our group has designed a DNA vaccine (HIVBr18) encoding a previously described set of eighteen conserved and multiple HLA-DR-binding HIV-1 CD4 ${ }^{+}$ $\mathrm{T}$ cell epitopes (HIVBr18). Peptides encoding such epitopes were recognized by PBMC from over 90\% of HIV-1 infected individuals [9]. Immunization of different strains of mice, including BALB/c and mice transgenic to common HLA class II alleles, with the multiepitope DNA vaccine induced responses to 17 out of the 18 epitopes encoded by the vaccine $[10,11]$. Moreover, the induced $\mathrm{CD}^{+}$and $\mathrm{CD}^{+} \mathrm{T}$ cells were polyfunctional and long-lived with central and memory phenotype [11]. By virtue of inducing broad responses against conserved $\mathrm{CD} 4^{+} \mathrm{T}$ cell epitopes that could be recognized across widely diverse common

*Corresponding author: Edecio Cunha-Neto, Associate Professor, Division of Clinical Immunology and Allergy/LIM60, University of Sao Paulo School of Medicine (FM-USP), Sao Paulo, SP Brazil, Avenida Dr. Arnaldo, 455, sala 3209, Cerqueira Cesar, Sao Paulo, SP, Brazil, 01246-903, Tel: +55-11-30618315; Fax: +55-11-30618315; E-mail: edecunha@usp.br

Received September 01, 2011; Accepted November 25, 2011; Published December 02, 2011

Citation: Rosa DS, Ribeiro SP, Almeida RR, Mairena EC, Kalil J, et al. (2011) A Recombinant Adenovirus Encoding Multiple HIV-1 Epitopes Induces Stronger CD4 ${ }^{+} \mathrm{T}$ cell Responses than a DNA Vaccine in Mice. J Vaccines Vaccin 2:124 doi:10.4172/2157-7560.1000124

Copyright: ( 2011 Saridi M, et al. This is an open-access article distributed unde the terms of the Creative Commons Attribution License, which permits unrestricted use, distribution, and reproduction in any medium, provided the original author and source are credited. 
HLA class II alleles, this vaccine concept may cope both with HIV genetic variability and increase population coverage.

A polyfunctional $\mathrm{CD}^{+} \mathrm{T}$ cell response is a hallmark of HIV-1 patients who control viremia, and shows an inverse correlation with viral load [12,13]. It has been demonstrated that the efficacious smallpox and yellow fever vaccines induce durable, specific polyfunctional $\mathrm{CD} 4^{+}$ or $\mathrm{CD}^{+} \mathrm{T}$ cells $[14,16]$. Furthermore, vaccine-induced polyfunctional $\left(\mathrm{IFN} \gamma^{+} \mathrm{IL}-2^{+} \mathrm{TNFa}^{+}\right) \mathrm{CD}^{+} \mathrm{T}$ cell populations were shown to provide protection against Leishmania major [17] and M. tuberculosis [18] challenge.

Although DNA vaccines are highly immunogenic in small animal models, one of the most significant hurdles in developing such vaccines has been transferring the success of inducing protective immunity in those models [19] to larger animal models. Recombinant viral vectors have been used as an alternative to circumvent this problem. Indeed, vaccines based on adenovirus or cytomegalovirus vectors encoding SIV proteins were able to elicit broad, polyfunctional and durable $\mathrm{CD} 4^{+}$and $\mathrm{CD} 8^{+} \mathrm{T}$ cell responses and reduced viral load after challenge in nonhuman primates $[7,8]$. Several clinical trials have shown that vaccines based on replication-defective adenovirus serotype 5 (Ad5) are safe and highly immunogenic [20,23], even though the Ad5-vectored trivalent HIV vaccine tested in the STEP trial showed no protection [24]

Here we sought to test whether an Ad5 vector encoding the HIVBr18 epitopes (Ad5-HIVBr18) could increase the immunogenicity detected with DNA immunization. We observed that homologous prime-boost immunization using Ad5-HIVBr18 increased IFN- $\gamma$ / TNF- $\alpha$ production as well as proliferation of $\mathrm{CD} 4^{+}$and $\mathrm{CD} 8^{+} \mathrm{T}$ cells against vaccine-encoded peptides when compared to DNA vaccine immunization alone.

\section{Materials and Methods}

\section{Construction of a DNA vaccine and replication-defective recombinant adenovirus serotype 5 encoding multiple HIV-1 epitopes}

A DNA vaccine containing the codon optimized nucleotide sequence of the eighteen HIV-1 CD $4^{+}$epitopes described in Fonseca et al. [9]: p17 (73-89), p24 (33-45), p24 (131-150), p6 (32-46), pol (63-77), pol (136-150), pol (785-799), gp41(261-276), gp160 (19-31), gp160 (174-185), gp160 (188-201), gp160 (481-498), rev (11-27), vpr (58-72), vpr (65-82), vif (144-158), vpu (6-20) and nef (180-194) was constructed and produced as described in Ribeiro et al. and Rosa et al. $[10,11]$. The numbers in brackets are amino acid positions in reference HIV-1 strain HXB2. A replication-defective E1-deleted recombinant adenovirus serotype 5 (Ad5) encoding the HIVBr18 sequence (Ad5HIVBr18) was commercially generated (ViraQuest, Inc.). Briefly, the HIVBr18 insert was subcloned into pVQAd5CMVK-NpA shuttle plasmid (pVQAdCMV-HIVBr18). HEK293 cells were co- transfected with pVQAdCMV-HIVBr18 and the RAPAd backbone and harvested after 7 days.

The primary lysate was amplified and purified over two rounds of centrifugation on a $\mathrm{CsCl}$ gradient. The particles were isolated and dialyzed against A195 buffer and stored at $-80^{\circ} \mathrm{C}$. Construction of rAdlacZ, a recombinant adenovirus carrying the Escherichia coli galactosidase-coding sequence, described previously [25] was used as control and was kindly provided by Dr Maurício Rodrigues (Federal University of Sao Paulo- Brazil).

\section{Mice and Immunizations}

Six to eight weeks-old female BALB/c mice were used in this study.
Mice were maintained and manipulated under specific pathogen-free conditions at the animal care facilities of the Institute of Tropical Medicine, University of Sao Paulo (IMT/FMUSP). Experiments were performed in accordance to the guidelines of the Internal Review Board of University of Sao Paulo School of Medicine (CAPPesq- HCFMUSP) and approved under protocol number 775-06. For DNA immunization, six mice per group were injected with $7 \mu \mathrm{g}$ of cardiotoxin (Sigma) five days before vaccination and then received 3 doses of $100 \mu \mathrm{g}$ of HIVBr18 or empty vector pVAX1 intramuscularly (IM) at days 0,15 and 30 . Each quadriceps was injected with $50 \mu \mathrm{L}$ of DNA at a concentration of $1 \mu \mathrm{g} / \mu \mathrm{L}$ in saline. For adenovirus immunization, mice were inoculated subcutaneously (SC) or intramuscularly (IM) with viral suspension (Ad5-HIVBr18 or Ad5- $\beta$ gal) containing $2 \times 10^{8} \mathrm{PFU}$ at days 0 and 15 . For heterologous prime-boost regimens, animals received cardiotoxin (Sigma) five days before vaccination with HIVBr18 (IM) and fifteen days later received $2 \times 10^{8} \mathrm{PFU}$ of Ad5-HIVBr18 by IM or SC route.

\section{Peptides}

The eighteen multiple HLA-DR binding, frequently recognized peptides, derived from the conserved regions of HIV-1 B-subtype consensus and selected from the whole proteome [9] were synthesized in house by solid phase technology using the 9-fluorenylmethoxycarbonyl (Fmoc) strategy, with the C-terminal carboxyl group in amide form [26]. Peptide purity and quality were assessed by reverse-phase high performance liquid chromatography and mass spectrometry and was routinely above $90 \%$.

\section{Spleen cell isolation}

Two or 28 weeks after the last immunization, mice were euthanized and spleens were removed aseptically. After obtaining single cell suspensions, cells were washed in RPMI 1640. Cells were then ressuspended in R-10 (RPMI supplemented with $10 \%$ of fetal bovine serum (FBS-GIBCO), $2 \mathrm{mM}$ L-glutamine (Sigma), $10 \mathrm{mM}$ Hepes (Sigma), $1 \mathrm{mM}$ sodium pyruvate, $1 \% \mathrm{vol} / \mathrm{vol}$ non-essential aminoacids solution, $40 \mu \mathrm{g} / \mathrm{mL}$ of Gentamicin, $20 \mu \mathrm{g} / \mathrm{mL}$ of Peflacin and $5 \times 10^{-5} \mathrm{M}$ 2- mercaptoethanol (SIGMA). Cell viability was evaluated using $0.2 \%$ Trypan Blue exclusion dye to discriminate between live and dead cells.

\section{IFN- $\gamma$ ELISPOT assay}

Splenocytes from immunized mice were assayed for their ability to secrete IFN $-\gamma$ after in vitro stimulation with $5 \mu \mathrm{M}$ of individual or pooled HIV-1 peptides. The ELISPOT assay was performed using Becton Dickinson murine IFN- $\gamma$ ELISPOT kit, as previously described $[10,11]$. Spots were counted using AID ELISPOT Reader System (Autoimmun Diagnostika GmbH, Germany). The number of antigen specific T cells, expressed as spot-forming units (SFU) $/ 10^{6}$ splenocytes, was calculated after subtracting negative control values (medium only). The cutoff was calculated as the mean SFU $/ 10^{6}$ splenocytes $+3 \mathrm{SD}$ from pVAX1 and/or Ad5- $\beta$ gal immunized mice, stimulated with all peptides (cutoff $=15 \mathrm{SFU} / 10^{6}$ splenocytes).

\section{CFSE-based proliferation assay}

To monitor the expansion and proliferation of HIV-specific T cells, splenocytes from immunized mice were labeled with carboxyfluorescein succinimidyl ester (CFSE) (27). Briefly, freshly isolated splenocytes were resuspended $\left(50 \times 10^{6} / \mathrm{mL}\right)$ in PBS and labeled with $1.25 \mu \mathrm{M}$ of CFSE (Molecular Probes) at $37^{\circ} \mathrm{C}$ for 10 minutes. The reaction was quenched with RPMI 1640 supplemented with 10\% FBS and cells were washed before resuspending in RPMI 1640 at a density of $1.5 \times 10^{6} / \mathrm{mL}$. Cells were cultured in 96-well-round-bottomed plates $\left(3 \times 10^{5} /\right.$ well in 
triplicate) for 5 days at $37^{\circ} \mathrm{C}$ and $5 \% \mathrm{CO}_{2}$ with medium only or $5 \mu \mathrm{M}$ of HIV peptides. Positive control included cells stimulated with $2.5 \mu \mathrm{g} / \mathrm{mL}$ of Concanavalin A (Sigma). Cells were then harvested, washed with 100 $\mu \mathrm{L}$ of FACS buffer (PBS with $0.5 \%$ BSA and $2 \mathrm{mM}$ EDTA) and stained with anti-mouse $\mathrm{CD} 3$ phycoerythrin (PE), anti-mouse CD4 peridinin chlorophyll protein (PerCP) and anti-mouse CD8 allophycocyanin (APC) monoclonal antibodies (BD Pharmingen, San Jose, CA) for 45 minutes at $4^{\circ} \mathrm{C}$. Cells were then washed twice with FACS buffer, fixed with $4 \%$ paraformaldehyde, and resuspended in FACS buffer. Samples were acquired on a FACSCanto flow cytometer (BD Biosciences) and then analyzed using FlowJo software (version 9.0.2, Tree Star, San Carlo, CA). Fifty thousand events were acquired in a live lymphocyte gate. The percent of proliferating $\mathrm{CD}^{+}$and $\mathrm{CD}^{+} \mathrm{CFSE}^{\text {low }}$ cells was determined in the $\mathrm{CD}^{+}$cell population and the criteria for scoring as positive included \% CFSE ${ }^{\text {low }}$ cells > cutoff. The cutoff of unspecific proliferative response was determined based on the percentage of proliferating cells (\% of $\mathrm{CD}^{+} \mathrm{CD} 4^{+}$or $\mathrm{CD}^{+}{ }^{+} \mathrm{CD} 8^{+} \mathrm{CFSE}^{\text {low }}$ cells) on splenocytes from pVAX1 and/ or Ad5- $\beta$ gal immunized groups after stimulating with individual peptides +3 standard deviation (SD).

\section{Analysis of polyfunctional HIV-specific T-cell responses}

Splenocytes from immunized mice were labeled with CFSE as described above. CFSE-labeled cells were incubated at a density of $2.5 \times 10^{6} \mathrm{cells} / \mathrm{mL}$ and cultured in 96 -well-round-bottomed plates $\left(5 \times 10^{5} /\right.$ well in triplicate) for 4 days at $37^{\circ} \mathrm{C}$ and $5 \% \mathrm{CO}_{2}$ with medium only or pooled HIV peptides $(5 \mu \mathrm{M})$. After 4 days of incubation, cells were restimulated in the presence of $2 \mu \mathrm{g} / \mathrm{mL}$ anti-CD28 (BD Pharmingen), $5 \mu \mathrm{M}$ of pooled HIV peptides and Brefeldin A- GolgiPlug ${ }^{\mathrm{TM}}$ (BD Pharmingen) for the last 12 hours. After the incubation period, cells were washed with FACS buffer and surface stained using monoclonal antibodies to CD8-Alexa700 and CD4- PerCP for 30 minutes at $4^{\circ} \mathrm{C}$. Cells were fixed and permeabilized using the Cytofix/Cytoperm ${ }^{\mathrm{TM}} \mathrm{kit}$ (BD Pharmingen). Permeabilized cells were washed with Perm/Wash buffer (BD Biosciences) and stained with monoclonal antibodies to CD3-APCCy7, IL2-PE, TNFa-PECY7 and IFN $\gamma$ - APC for 30 minutes at $4^{\circ} \mathrm{C}$. Following staining, cells were washed twice and resuspended in FACS buffer. All antibodies were from BD Pharmingen. Samples were acquired on a FACSCanto flow cytometer (BD Biosciences) and then analyzed using FlowJo software (version 9.0.2, Tree Star, San Carlo, CA). Five hundred thousand events were acquired in a live lymphocyte gate. The percent of cytokine producing and proliferating $\mathrm{CD} 4^{+}$and $\mathrm{CD}^{+}$cells was determined in the $\mathrm{CD}^{+}$cell population. In addition, we used Boolean gate (FlowJo software (version 9.0.2, Tree Star, San Carlo, CA)) platform to create several combinations of the cytokine gates among the proliferating $\mathrm{T}$ cells resulting in seven distinct patterns. The percentages of cytokine- producing cells were calculated by subtracting background values. For each flow cytometry experiment performed in this paper, unstained and all single-color controls were processed to allow proper compensation.

\section{Data Analysis}

Statistical significance (p-values) was calculated by using One-way ANOVA and Tukey's honestly significantly different (HSD) or Twoway ANOVA and Bonferroni Post Test.

\section{Results}

To analyze whether the Ad5-HIVBr18 vaccine could be more immunogenic than the DNA counterpart, HIVBr18, BALB/c mice were immunized with either the previously established DNA immunization protocol (3 doses of HIVBr18 [13,14]); or with 2 doses of Ad5-HIVBr18 by different routes; or with a heterologous DNA prime (HIVBr18) followed by Ad5-HIVBr18-boost by different routes. Fifteen days after the last immunization, pooled splenocytes were evaluated for specific $\mathrm{CD} 4^{+}$and $\mathrm{CD} 8^{+} \mathrm{T}$ cell proliferation against pooled HIV-1 peptides by the CFSE-based proliferation assay. CD $4^{+}$ and $\mathrm{CD}^{+} \mathrm{T}$ cells from animals that received two doses of recombinant adenovirus subcutaneously (Ad5-HIVBr18, SC) presented significantly higher specific proliferation than the group immunized with 3 doses of the HIVBr18 DNA vaccine (Figure 1). HIV-specific proliferation was above $20 \%$ for $\mathrm{CD}^{+}$and above $10 \%$ for $\mathrm{CD}^{+} \mathrm{T}$ cells in this group, being significantly higher for the $\mathrm{CD}^{+} \mathrm{T}$ cell compartment than the $\mathrm{CD} 8^{+} \mathrm{T}$ cell compartment $(\mathrm{p}<0.05)$. Neither of the heterologous prime-boost regimens was able to increase the magnitude of $\mathrm{CD}^{+}$ and $\mathrm{CD}^{+} \mathrm{T}$ cell proliferative responses as compared to the HIVBr18 DNA immunization protocol. Actually, the heterologous prime-boost protocols were associated with a decrease in the magnitude of the proliferative responses.

We subsequently characterized the cytokine production profile of the specific T cells. Using the IFN- $\gamma$ ELISPOT assay, we observed that splenocytes from animals that received two doses of Ad5-HIVBr18 (SC) presented significantly higher IFN- $\gamma$ secretion when compared with those immunized with HIVBr18 DNA alone (Figure 2A). Both heterologous prime-boost regimens reduced the magnitude of the responses.

In order to assess the functional profile of the induced $\mathrm{CD} 4^{+}$and $\mathrm{CD}^{+} \mathrm{T}$ cells, we performed a multiparameter flow cytometry analysis. This strategy allowed us to characterize the antigen-specific $\mathrm{T}$ cells based on their ability to proliferate and produce the effector cytokines IFN- $\gamma$, TNF- $\alpha$ and IL-2 at a single cell level. Taking into account cells that proliferated and produced any of the 3 cytokines tested, we observed that subcutaneous immunization with Ad5-HIVBr18 induced significantly higher $\mathrm{CD} 4^{+} \mathrm{T}$ cells with such profile. On the other hand, heterologous prime-boost protocols induced significantly lower

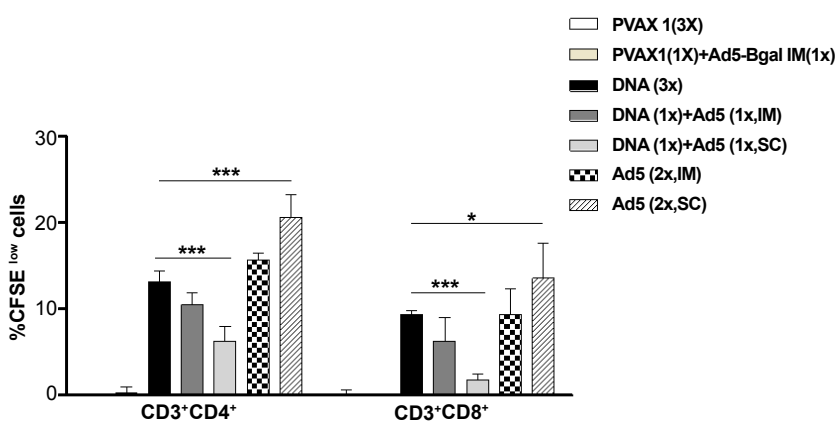

Figure 1: Immunization with an adenovirus encoding the multiepitope gene (Ad5-HIVBr18) elicits higher proliferative responses when compared to other regimens. BALB/c mice (6 per group) were immunized intramuscularly (IM) with the DNA vaccine HIVBr18 (3 doses); or received 2 doses of $2 \times 10^{\circ}$ PFU of recombinant adenovirus (Ad5) by intramuscular (IM) or subcutaneous (SC) route; or received a heterologous prime-boost regimen based on a DNA prime (IM), Ad5 boost (IM or SC). Control groups received pVAX1 plasmid and/ or Ad5-ßgal.Two weeks after the last immunization; splenocytes from each immunized group were pooled, labeled with CFSE $(1.25 \mu \mathrm{M})$ and cultured for 5 days, in the presence of $5 \mu \mathrm{M}$ of pooled HIV-1 peptides. Cells were analyzed by flow cytometry and CFSE dilution on gated CD3+CD4+ or CD3+CD8+ cells was used as readout for antigen-specific proliferation. Cutoff values were $1.7 \%$ for CD4+ and $1.5 \%$ for CD8+ T cells. Only significant differences with the DNA immunized group are depicted $\left({ }^{*} p<0.05\right.$ and $\left.{ }^{* * *} p<0.001\right)$. DNA $=\operatorname{HIVBr} 18$; Ad5= adenovirus 5 encoding HIVBr18. 

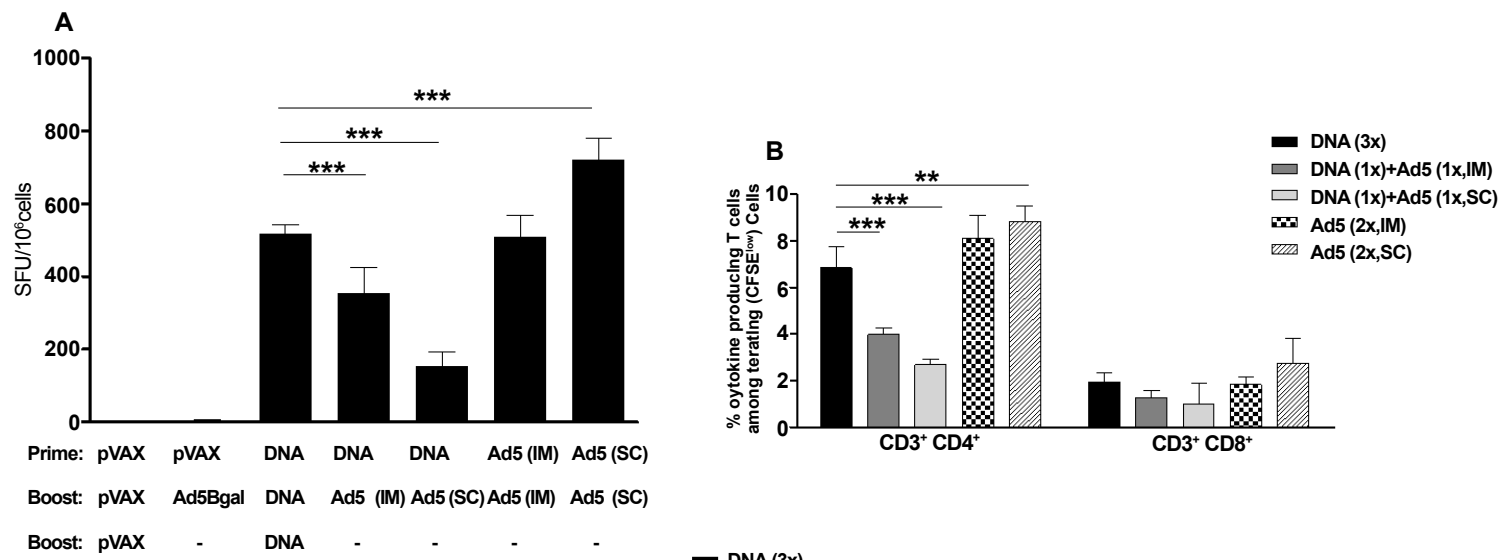

DNA (3x)

$\square$ DNA (1x)+Ad5 (1x,IM)

$\square$ DNA $(1 \mathrm{x})+\mathrm{Ad} 5(1 \mathrm{x}, \mathrm{SC})$

$\mathbf{W}$ Ad5 (2x,IM)

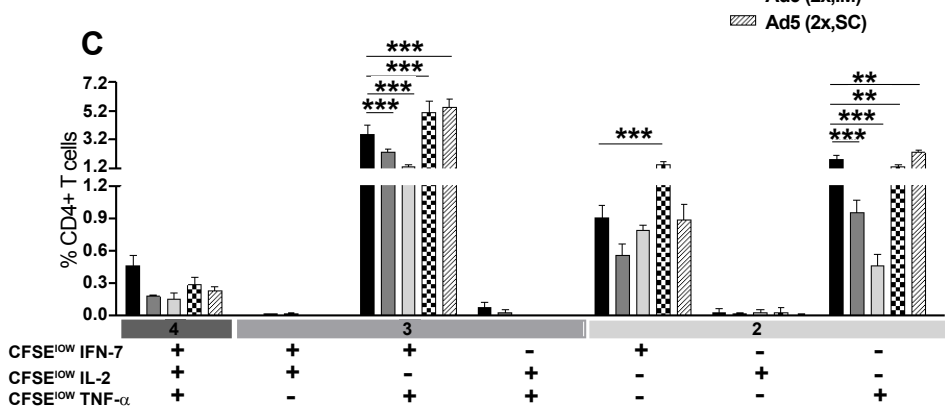

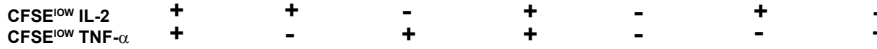

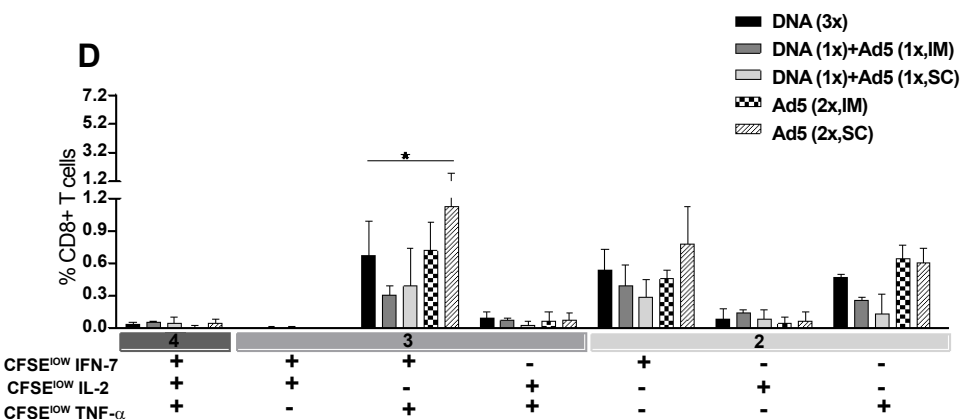

Figure 2: Immunization with Ad5-HIVBr18 induces higher number of polyfunctional T cells when compared to other regimens. BALB/c mice (6 per group) were immunized as described in Figure 1 and Methods section. Two weeks after the last immunization, splenocytes from each immunized group were pooled and specific immune responses were evaluated in vitro against pooled HIV-1 peptides. (A) Frequencies of IFN- $\gamma$ secreting cells measured by ELISPOT. SFU, spot-forming units. Cutoff: $15 \mathrm{SFU} / 10^{6}$. (B) Splenocytes were labeled with CFSE $(1.25 \mu \mathrm{M})$ and cultured for 4 days in the presence of pooled HIV-1 peptides or medium only. On day 4 , cells were pulsed for 12 hours with pooled peptides in the presence of costimulatory antibody and Brefeldin A. Cells were then surface stained with antibodies to CD4 and CD8, permeabilized and stained for intracellular cytokines (IFN- $\gamma$, TNF- $\alpha$ and IL-2) and CD3. Total frequencies of proliferating (CFSElow) and cytokine-producing CD4+ and CD8+ T cells are shown. (C) and (D) After gating on proliferating (CFSElow) and cytokine-producing cells, Boolean combinations were created using FlowJo software to determine the frequency of each response based on all possible combinations of cytokine expression among proliferating $T$ cells. Splenocytes from control groups ( $p$ VAX1 and/or Ad5- $\beta$ gal) presented negligible numbers of IFN- $\gamma$ secreting cells and proliferating-cytokine producing cells. Only significant differences with the DNA immunized group are depicted $\left({ }^{*} p<0.05,{ }^{* *} p<0.01\right.$ and $\left.{ }^{* * *} p<0.001\right)$. DNA= HIVBr18; Ad5= adenovirus 5 encoding HIVBr18.

responses as compared to immunization with HIVBr18 DNA alone. The induced HIV-1-specific CD4 ${ }^{+} \mathrm{T}$ cell responses were significantly higher than $\mathrm{CD}^{+} \mathrm{T}$ cell responses in all immunization groups $(\mathrm{p}<0.01)$, except for the subcutaneous heterologous prime-boost regimen (Figure $2 \mathrm{~B})$. There was no significant difference in the magnitude of the $\mathrm{CD} 8^{+} \mathrm{T}$ cell induced immune responses among different groups.

Boolean combinations allowed us to evaluate the polyfunctional profile of the induced T cells based on the ability of these cells to perform any of the above measured functions (proliferation and cytokine production). Boolean analysis of proliferating $\left(\mathrm{CFSE}^{\text {low }}\right)$ and cytokinepositive populations indicated that all immunized groups presented a similar $\mathrm{CD}^{+} \mathrm{T}$ cell polyfunctional profile (Figure 2C). However, Ad5-HIVBr18 immunization induced a significantly higher number of peptide-specific $\mathrm{CD} 4^{+} \mathrm{T}$ cells that were able to proliferate and produce IFN- $\gamma$ and TNF- $\alpha$, alone or in combination, than immunization with HIVBr18 (Figure 2C). On the other hand, heterologous prime-boost regimens induced significantly lower numbers of proliferating $\mathrm{CD}^{+}$ $\mathrm{T}$ cells producing TNF- $\alpha$ alone or in combination with IFN $-\gamma$, as compared to $\mathrm{HIVBr} 18$. We also found that for the $\mathrm{CD} 8^{+} \mathrm{T}$ cell subset, 

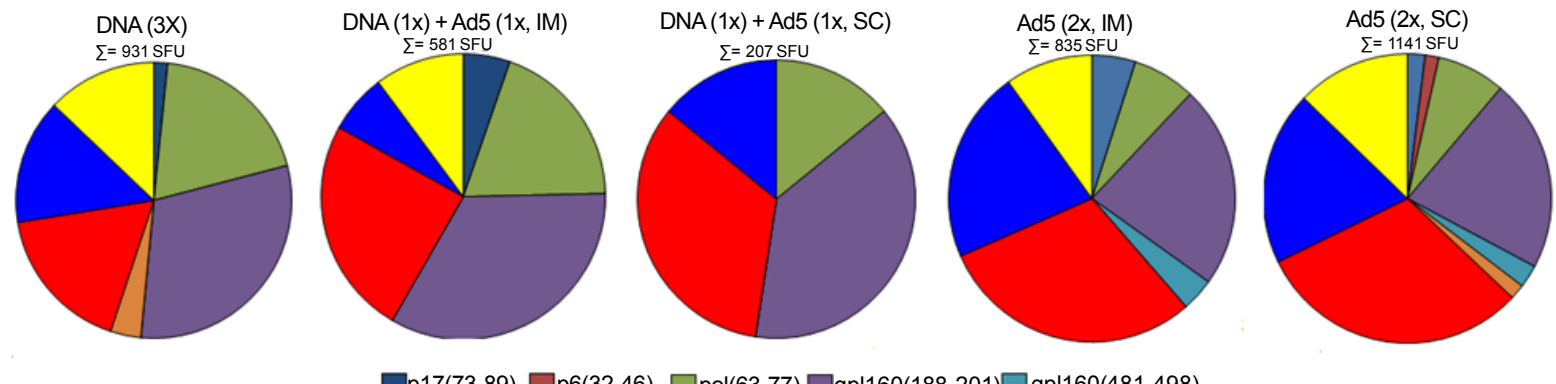

$\square$ 17(73-89) $\square \mathrm{p} 6(32-46)$

$\square \operatorname{pol}(63-7$

gpl160(188-201) $\square g$ gpl160(481-498)

$\operatorname{rev}(11-27)$

$\operatorname{Vpr}(65-82) \square \operatorname{Vif}(144-158)$

nef(180-194)

Figure 3: Breadth of immune responses. BALB/c mice were immunized as described in Figure 1 and Methods section. Two weeks after the last immunization, splenocytes from immunized mice (6 per group) were pooled and the specific IFN- $\gamma$ responses were evaluated in vitro against 18 individual HIV-1 peptides encoded by the vaccines $(5 \mu \mathrm{M})$. The pie charts show the frequencies of HIV-1 peptide-specific IFN- $\gamma$ secreting cells by displaying each number of SFU/10 ${ }^{6}$ cells for each positive peptide as a proportion of the sum of SFU $/ 10^{6}$ cells for all positive peptides. The sum of all positive responses (SFU/10 cells) is shown above each pie chart. Splenocytes from control groups (pVAX1 and/or Ad5-ßgal) presented negligible numbers of IFN- $\gamma$ secreting cells after stimulation with each of the 18 encoded peptides. SFU, spot-forming units. Cutoff: $15 \mathrm{SFU} / 10^{6}$

there was a higher prevalence of proliferating cells that produced IFN- $\gamma$ and TNF- $\alpha$, alone or simultaneously, in all immunized groups (Figure 2D). $\mathrm{CD}^{+} \mathrm{T}$ cells from mice subcutaneously immunized with Ad5HIVBr18 presented higher percentages of CFSE ${ }^{\text {low }}$ and IFN- $\gamma /$ TNF- $\alpha$ producing cells than HIVBr18. Control groups (pVAX1 or Ad5- $\beta$ gal immunized group) presented negligible levels of cytokine producingproliferating $\mathrm{T}$ cells. These results showed that immunization protocols based on Ad5 vector, especially by the subcutaneous route, can generate proliferating and cytokine-producing specific $\mathrm{T}$ cells with higher magnitude than DNA immunization. On the other hand, the heterologous prime-boost regimens frequently reduced the responses as compared to immunization with HIVBr18.

In order to verify if immunization protocols based on Ad5 vector would be able to induce a broader specific immune response, we performed IFN- $\gamma$ ELISPOT assays stimulated with each of the $18 \mathrm{HIV}-1$ peptides encoded by the vaccines. While immunization with HIVBr18 induced responses to 7 peptides, subcutaneous immunization with Ad5-HIVBr18 induced responses to 2 additional peptides: (p6(32-46) and gp160(481-498)) (Figure 3). These results show that the selected viral vector was able to increase the magnitude and, to a lesser extent, also had an impact in the breath of the immune responses against the vaccine encoded epitopes.

Given the importance of long-term vaccine induced immune responses, we evaluated the presence of specific T cells 28 weeks after the last immunization. As shown in Figure 4, measurable proliferative responses were observed at this time point, and proliferative $\mathrm{CD} 4^{+}$ $\mathrm{T}$ cell responses were significantly higher in the group immunized subcutaneously with Ad5-HIVBr18 than HIVBr18. The heterologous prime-boost regimens induced the lowest proliferative responses at the 28 week time-point, as previously observed for the 2 week time-point.

The ability of $\mathrm{T}$ cells from immunized mice to secrete cytokines over time was also evaluated by IFN- $\gamma$ ELISPOT (Figure 5A) and multiparametric flow cytometry assays (Figure $5 \mathrm{~B}-\mathrm{C}$ ). IFN- $\gamma$ secretion was detectable in all immunized groups at the 28 week-time point and was significantly higher in the group subcutaneously immunized with Ad5-HIVBr18 than in the HIVBr18 immunized group (Figure $5 \mathrm{~A}$ ). Boolean analysis showed that different immunization protocols induced 4 to $9 \%$ of $\mathrm{CD}^{+}{ }^{+} \mathrm{T}$ cells that proliferated and produced at least one cytokine in response to pooled HIV-1 peptides (Figure 5B).
Proliferating/cytokine producing $\mathrm{CD}^{+} \mathrm{T}$ cells were significantly higher among the Ad5-HIVBr18 immunized groups. Boolean analysis at this time point (28 weeks) showed that Ad5-HIVBr18 immunization induced higher numbers of peptide-specific $\mathrm{CD} 4^{+} \mathrm{T}$ cells that proliferate $\left(\mathrm{CFSE}^{\text {low }}\right)$ and produce IFN- $\gamma / \mathrm{TNF}-\alpha$ simultaneously (Figure $5 \mathrm{C}$ ) and that proliferate and produce IFN- $\gamma$ alone than HIVBr18 immunized group. These results showed that immunization protocols based on adenovirus 5, mainly by the subcutaneous route, can generate a more durable specific immune response than DNA immunization. On the other hand, heterologous prime boost regimens reduced the magnitude of specific immune responses.

Finally, we evaluated the breadth of the induced immune responses at the 28 week-time point for all immunized groups by IFN- $\gamma$ ELISPOT assay. The number of recognized peptides varies from 2 to 9 (Figure 6 ). The broadest response was observed in the group immunized with HIVBr18. Comparison of the 2- and 28-week time points showed different epitope targets. Responses to peptide gp160(481-498) found 2 weeks after last immunization with Ad5-HIVBr18 (Figure 3) were not detected anymore at the 28 week-time point, while responses to $\mathrm{p} 24(33-45)$ and pol(785-799) became borderline positive in the HIVBr18-immunized group. With the exception of p17(73-89), all responses were higher in mice immunized subcutaneously with Ad5HIVBr18 than HIVBr18. These results showed that subcutaneous administration of Ad5-HIVBr18 had an impact at the magnitude of the induced immune responses over time.

\section{Discussion}

In this paper, we have shown that immunization with Ad5HIVBr18 induced stronger $T$ cell responses than HIVBr18, the previously described DNA vaccine [10,11], without impairing the breadth of the immune responses. Ad5-HIVBr18-immunized mice displayed significantly higher proliferative, as well as polyfunctional $\mathrm{CD}^{+}$and $\mathrm{CD}^{+} \mathrm{T}$ cell responses when compared to HIVBr18. Most of these responses were highest among animals immunized with Ad5-HIVBr18 by the subcutaneous route. The same immunization protocol induced the highest $\mathrm{T}$ cell immune responses even at 28 weeks after the last immunization, indicating that it was also able to improve the longevity of the vaccine-induced immune responses, as compared to DNA immunization. The Ad5-HIVBr18 immunization 


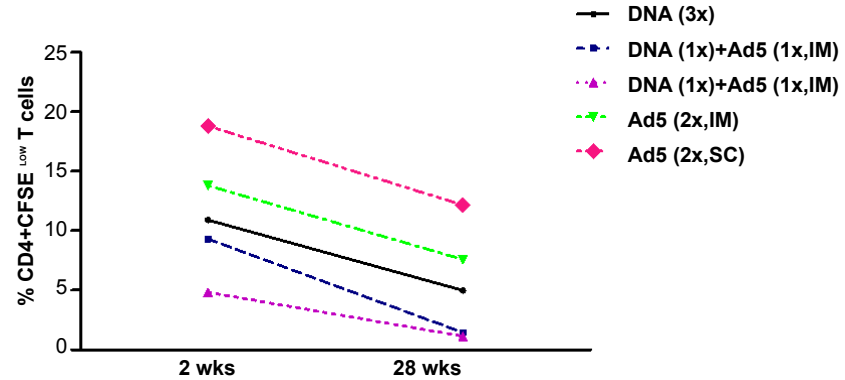

Figure 4: Ad5-HIVBr18 immunization induces higher proliferative responses up to 28 weeks after the last immunization. BALB/c mice were immunized as described earlier. Twenty-eight weeks after the last immunization, splenocytes from immunized mice (6 per group) were pooled, labeled with CFSE $(1.25 \mu \mathrm{M})$ and cultured for 5 days, in the presence of $5 \mu \mathrm{M}$ of pooled HIV-1 peptides. Cells were analyzed by flow cytometry and CFSE dilution on gated CD3+CD4+ or CD3+CD8+ cells was used as readout for antigen-specific proliferation. Experimental groups presented proliferation above cutoff values in all time points. The average of proliferation on splenocytes from pVAX1 and/or Ad5- $\beta$ gal immunized group was subtracted from the respective experimental groups. DNA= HIVBr18; Ad5= adenovirus 5 encoding HIVBr18. DNA vs Ad5 (2x, SC), $p<0.001$.

strategy maintained the bias toward $\mathrm{CD}^{+} \mathrm{T}$ cell responses, as previously observed for HIVBr18 [10,11]. An additional advantage of immunization with Ad5-HIVBr18 as compared to HIVBr18 was the reduced number of required doses ( 2 vs. 3 doses, respectively). We also tested heterologous prime-boost protocols, which were invariably less efficient than homologous immunization regimens.

As mentioned above, we observed that homologous adenovirusbased immunization protocols increased the magnitude of specific proliferation and type 1 cytokine production, in both $\mathrm{CD} 4^{+}$and $\mathrm{CD} 8^{+}$ $\mathrm{T}$ cell subsets. This is of great interest, since adenovirus-based vaccines that induced highly immunogenic responses in mice [28] and nonhuman primate models [8] were able to control pathogen specific challenge. In Addition, it did not impair the breadth of these responses.

Interestingly, we observed that the $\mathrm{CD}^{+} \mathrm{T}$ cell response was significantly higher than the $\mathrm{CD} 8^{+}$response among adenovirus-based vaccine immunized groups. This is in contrast with previous reports that showed that adenovirus vector-based immunization induces a stronger $\mathrm{CD}^{+}$than $\mathrm{CD}^{+} \mathrm{T}$ cell response [29]. We believe that the CD4-biased immune responses may be due to the intrinsic design of the CD4 T cell epitope-rich insert, as previously observed by our group with HIVBr18 immunization [10,11]. Although Ad5-HIVBr18 immunization induced a CD4-biased $\mathrm{T}$ cell response, it also improved $\mathrm{CD} 8^{+}$specific $\mathrm{T}$ cell responses, when compared to HIVBr18 immunization.

In the present work, all immunization strategies were able to induce polyfunctional $\mathrm{T}$ cells. However, we found a significantly increased number of polyfunctional $\mathrm{CD}^{+}$and $\mathrm{CD}^{+} \mathrm{T}$ cells in Ad5-HIVBr18immunized group when compared to HIVBr18. A polyfunctional $\mathrm{CD}^{+} \mathrm{T}$ cell response is a hallmark of HIV-1 patients who control viremia, and shows an inverse correlation with viral load $[12,13]$. In mice, vaccine-induced polyfunctional $\mathrm{CD} 4^{+} \mathrm{T}$ cells have been shown to correlate with protection against Leishmania major [17] and $M$. tuberculosis [18].

We found that subcutaneous immunization with Ad5-HIVBr18 increased the number of recognized epitopes when compared to HIVBr18 vaccine. Indeed, the breadth of the immune responses has
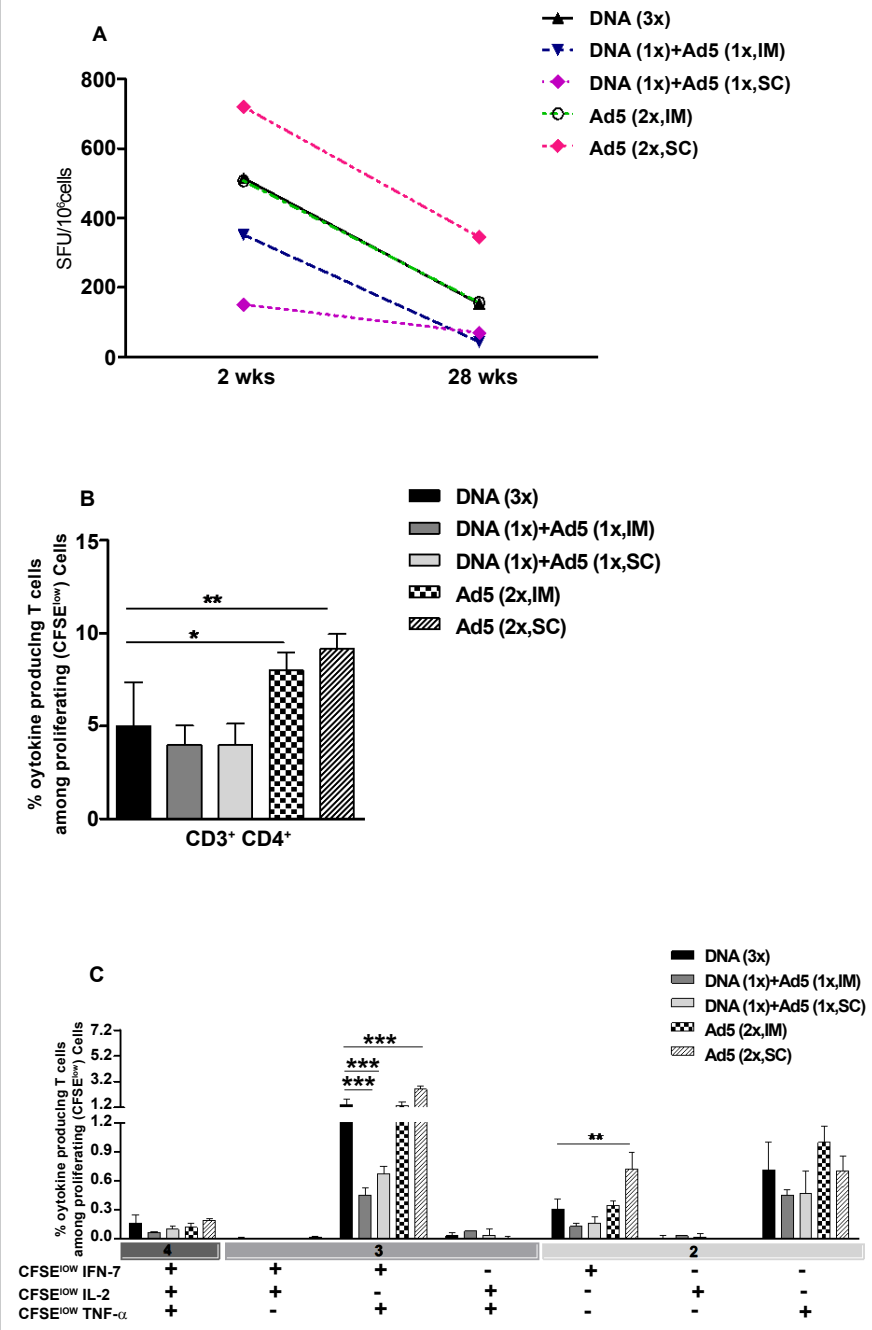

Figure 5: Ad5-HIVBr18 immunization induces higher numbers of polyfunctional T cells up to $\mathbf{2 8}$ weeks after the last immunization. BALB/C mice were immunized as described earlier. Twenty eight weeks after the last immunization, splenocytes from BALB/c mice (6 per group) were pooled and specific immune responses were evaluated in vitro against pooled HIV1 peptides. (A) Frequencies of IFN- $\gamma$ secreting cells measured by ELISPOT. (B) Spleen cells were labeled with CFSE $(1.25 \mu \mathrm{M})$ and cultured for 4 days in the presence of pooled HIV-1 peptides or medium only. On day 4 , cells were pulsed for 12 hours with pooled peptides in the presence of costimulatory antibody and Brefeldin A. Cells were then surface stained with antibodies to CD4 and CD8, permeabilized and stained for intracellular cytokines and CD3. Total frequencies of proliferating (CFSElow) and cytokine-producing CD4+ T cells are shown. (C). Values from control groups ( $p$ VAX1 and/or Ad5-ßgal) were subtracted from experimental groups and are not depicted. DNA= HIVBr18; Ad5= adenovirus 5 encoding HIVBr18. DNA vs DNA (1x) + Ad5 (1x, IM), $p<0.001$; DNA vs DNA (1x) + Ad5 (1x, SC), $p<0.001$; DNA vs Ad5 (2x, $\mathrm{SC}), \mathrm{p}<0.001$

been suggested as a correlate of protection in HIV-1/SIV infection $[30-33,8]$. By virtue of inducing broad responses against conserved $\mathrm{CD} 4^{+} \mathrm{T}$ cell epitopes, this vaccine concept may cope with HIV genetic variability and viral escape.

Beyond the magnitude and breadth of the induced immune responses, long-term immunity is critical and has an important impact on vaccine-induced protection [16]. We observed a persistent specific immune response up to 28 weeks after the last dose for all immunized 

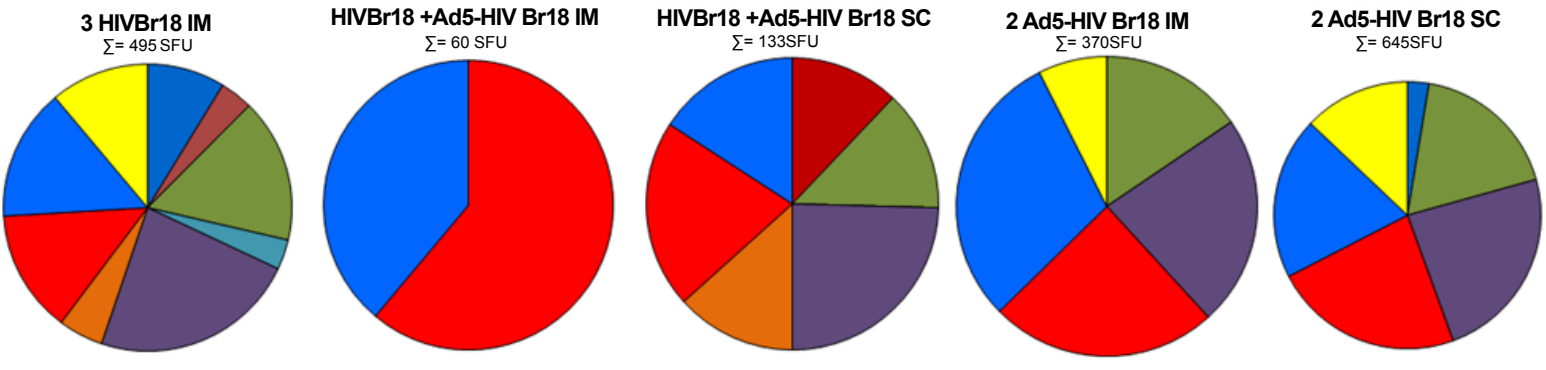

$\square$ p17(73-89) $\square$ p24(33-45)

p6(32-46)

pol(63-77)

$\operatorname{pol}(785-799) \square g$ 160(188-201)

$\square \operatorname{rev}(11-27) \square \operatorname{vpr}(65-82) \square \operatorname{vif(144-158)} \square \operatorname{nef}(180-194)$

Figure 6: Breadth of immune responses 28 weeks after last dose. BALB/c mice were immunized as described earlier. Twenty eight weeks after the last immunization, splenocytes from immunized mice ( 6 per group) were pooled and the specific IFN- $\gamma$ responses were evaluated in vitro against 18 individual HIV-1 peptides encoded by the vaccines $(5 \mu \mathrm{M})$. (A) The pie charts represent the frequencies of HIV-1 peptide-specific IFN- $\gamma$ secreting cells by displaying each number of SFU $/ 10^{6}$ cells for each positive peptide as a proportion of the sum of SFU $/ 10^{6}$ cells for all positive peptides. The sum of all positive responses (SFU/10 cells) is shown above each pie chart. Splenocytes from control groups ( $p$ VAX1 and/or Ad5-ßgal) presented negligible numbers of IFN- $\gamma$ secreting cells after stimulation with each of the 18 encoded peptides. SFU, spot-forming units. Cutoff: 15 SFU/106.

groups, which was highest in the subcutaneously Ad5-HIVBr18 immunized group.

Heterologous prime-boost regimens have been proposed as an alternative to avoid boosting vector immunity and consequent impairment of the targeted immune responses. In our study, none of the heterologous DNA prime-Ad5 boost regimens were able to increase HIV- specific induced cellular immune responses when compared to HIVBr18 or Ad5-HIVBr18 alone. In fact, we have tested other heterologous DNA-prime adenovirus-boost combinations involving different number of doses of each immunogen, with similar or weaker responses (data not shown). This is in contrast with many reports that have shown that DNA prime and viral vector boost could be an effective strategy for eliciting strong $\mathrm{T}$-cell responses against pathogenic viruses such as Ebola virus, HIV, and HCV [34-36].

In spite of the high immunogenicity of Ad5-HIVBr18, there is a major concern in vaccination based on Ad5 viral vector. Most humans have high titers of neutralizing antibodies against this adenovirus serotype, due to the fact that natural Ad5 infection is commonly acquired in childhood. In addition, the use of adenovirus as a vector for HIV vaccines has been questioned after the results from the STEP trial. The trend toward increased acquisition of HIV-1 infection in baseline Ad5-seropositive vaccines was concerning but not statistically significant [24]. In addition, a recent report failed to find an association between Ad5 neutralizing antibody seropositivity and incidence of HIV acquisition among populations at elevated risk of HIV infection [37]. One way to overcome the pre-existing immunity problem is to use adenovirus serotypes with low prevalence of neutralizing antibodies [38]. To achieve this goal the development of vectors based on rare human serotypes such as human Ad35 [39], AdHu28 [40] or modification of the human Ad5 capsid [41,42] has been performed.

Altogether, our results showed that a recombinant adenovirus 5 vaccine expressing the CD4 epitope-rich HIVBr18 insert was highly immunogenic, especially when administered by the subcutaneous route. These results encourage the testing of an adenoviral vector-based HIVBr18 vaccine in non-human primates and future clinical trials.

\section{Acknowledgments}

This work was supported by NIH (5R03AI066961-03) and we thank Dr. Claudio Puschel and Mr. Washington Robert da Silva for peptide synthesis; Mr. Luis
Roberto Mundel for assistance at the animal facility. This research was supported by NIH Grant - NIAID 5R03AI066961-03, Brazilian National Research Council (CNPq), Sao Paulo State Research Funding Agency (FAPESP), International Centre of Genetic Engineering and Biotechnology (ICGEB) and by the Brazilian Ministry of Health (Brazil). S. P. Ribeiro and R. R. Almeida are recipients of a Sao Paulo State Research Funding Agency (FAPESP) fellowship.

\section{References}

1. Flynn NM, Forthal DN, Harro CD, Judson FN, Mayer KH, et al. (2005) Placebocontrolled phase 3 trial of a recombinant glycoprotein 120 vaccine to prevent HIV-1 infection. J Infect Dis 191: 654-665.

2. Kwong PD, Doyle ML, Casper DJ, Cicala C, Leavitt SA, et al. (2002) HIV-1 evades antibody-mediated neutralization through conformational masking of receptor-binding sites. Nature 420: 678-682.

3. Pitisuttithum P, Gilbert P, Gurwith M, Heyward W, Martin M, et al. (2006) Randomized, double-blind, placebo-controlled efficacy trial of a bivalent recombinant glycoprotein $120 \mathrm{HIV}-1$ vaccine among injection drug users in Bangkok, Thailand. J Infect Dis 194: 1661-1671.

4. Jin X, Newman MJ, De-Rosa S, Cooper C, Thomas E, et al. (2009) A novel HIV $T$ helper epitope-based vaccine elicits cytokine-secreting HIV-specific CD4+ T cells in a Phase I clinical trial in HIV-uninfected adults. Vaccine 27: 7080-7086.

5. McElrath MJ, De Rosa SC, Moodie Z, Dubey S, Kierstead L, et al. (2008) HIV1 vaccine-induced immunity in the test-of-concept Step Study: a case-cohort analysis. Lancet 372: 1894-1905.

6. Rerks-Ngarm S, Pitisuttithum P, Nitayaphan S, Kaewkungwal J, Chiu J, et al (2009) Vaccination with ALVAC and AIDSVAX to prevent HIV-1 infection in Thailand. N Engl J Med 361: 2209-20.

7. Hansen SG, Vieville C, Whizin N, Coyne-Johnson L, Siess DC, et al. (2009) Effector memory $\mathrm{T}$ cell responses are associated with protection of rhesus monkeys from mucosal simian immunodeficiency virus challenge. Nat Med 15 293-299.

8. Wilson NA, Keele BF, Reed JS, Piaskowski SM, MacNair CE, et al. (2009) Vaccine-induced cellular responses control simian immunodeficiency virus replication after heterologous challenge. J Virol 83: 6508-6521.

9. Fonseca SG, Coutinho-Silva A, Fonseca LA, Segurado AC, Moraes SL, et al. (2006) Identification of novel consensus CD4 T-cell epitopes from clade B HIV-1 whole genome that are frequently recognized by HIV-1 infected patients. AIDS 20: 2263-2273.

10. Ribeiro SP, Rosa DS, Fonseca SG, Mairena EC, Postol E, et al. (2010) A vaccine encoding conserved promiscuous HIV CD4 epitopes induces broad T cell responses in mice transgenic to multiple common HLA class II molecules. PLoS One 5: e11072.

11. Rosa DS, Ribeiro SP, Almeida RR, Mairena EC, Postol E, et al. (2011) A DNA vaccine encoding multiple HIV CD4 epitopes elicits vigorous polyfunctional, long-lived CD4+ and CD8+ T cell responses. PLoS One 6: e16921. 
Citation: Rosa DS, Ribeiro SP, Almeida RR, Mairena EC, Kalil J, et al. (2011) A Recombinant Adenovirus Encoding Multiple HIV-1 Epitopes Induces Stronger $\mathrm{CD}^{+}{ }^{+} \mathrm{T}$ cell Responses than a DNA Vaccine in Mice. J Vaccines Vaccin 2:124. doi:10.4172/2157-7560.1000124

12. Ferre AL, Hunt PW, McConnell DH, Morris MM, Garcia JC, et al. (2010) HIV controllers with HLA-DRB1*13 and HLA-DQB1*06 alleles have strong polyfunctional mucosal CD4+ T-cell responses. J Virol 84: 11020-11029.

13. Kannanganat S, Kapogiannis BG, Ibegbu C, Chennareddi L, Goepfert P, et al (2007) Human immunodeficiency virus type 1 controllers but not noncontrollers maintain CD4 T cells coexpressing three cytokines. J Virol 81: 12071-12076.

14. Akondy RS, Monson ND, Miller JD, Edupuganti S, Teuwen D, et al. (2009) The yellow fever virus vaccine induces a broad and polyfunctional human memory CD8+ T cell response. J Immunol 183: 7919-7930.

15. Gaucher D, Therrien R, Kettaf N, Angermann BR, Boucher G, et al. (2008) Yellow fever vaccine induces integrated multilineage and polyfunctional immune responses. J Exp Med 205: 3119-3131.

16. Precopio ML, Betts MR, Parrino J, Price DA, Gostick E, et al. (2007) Immunization with vaccinia virus induces polyfunctional and phenotypically distinctive CD8(+) T cell responses. J Exp Med 204: 1405-1416.

17. Darrah PA, Patel DT, De Luca PM, Lindsay RW, Davey DF, et al. (2007) Multifunctional $\mathrm{TH} 1$ cells define a correlate of vaccine-mediated protection against Leishmania major. Nat Med 13: 843-850.

18. Lindenstrom T, Agger EM, Korsholm KS, Darrah PA, Aagaard C, et al. (2009) Tuberculosis subunit vaccination provides long-term protective immunity characterized by multifunctional CD4 memory T cells. J Immunol 182: 80478055.

19. Kutzler MA, Weiner DB (2008) DNA vaccines: ready for prime time? Nat Rev Genet 9: 776-788.

20. Catanzaro AT, Koup RA, Roederer M, Bailer RT, Enama ME, et al. (2006) Phase 1 safety and immunogenicity evaluation of a multiclade HIV-1 candidate vaccine delivered by a replication-defective recombinant adenovirus vector. J Infect Dis 194: 1638-1649.

21. Jaoko W, Karita E, Kayitenkore K, Omosa-Manyonyi G, Allen S, et al. (2010) Safety and immunogenicity study of Multiclade HIV-1 adenoviral vector vaccine alone or as boost following a multiclade HIV-1 DNA vaccine in Africa. PLoS One 5: e12873.

22. Peiperl L, Morgan C, Moodie Z, Li H, Russell N, et al. (2010) Safety and immunogenicity of a replication-defective adenovirus type $5 \mathrm{HIV}$ vaccine in Ad5-seronegative persons: a randomized clinical trial (HVTN 054). PLoS One 5: e13579.

23. Priddy FH, Brown D, Kublin J, Monahan K, Wright DP, et al. (2008) Safety and immunogenicity of a replication-incompetent adenovirus type 5 HIV-1 clade B $\mathrm{gag} / \mathrm{pol} / \mathrm{nef}$ vaccine in healthy adults. Clin Infect Dis 46: 1769-1781.

24. Buchbinder SP, Mehrotra DV, Duerr A, Fitzgerald DW, Mogg R, et al. (2008) Efficacy assessment of a cell-mediated immunity HIV-1 vaccine (the Step Study): a double-blind, randomised, placebo-controlled, test-of-concept trial. Lancet 372: 1881-1893.

25. Bruna-Romero O, Lasarte JJ, Wilkinson G, Grace K, Clarke B, et al. (1997) Induction of cytotoxic T-cell response against hepatitis $\mathrm{C}$ virus structural antigens using a defective recombinant adenovirus. Hepatology 25: 470-477.

26. Atherton ND (1989) HPLC measurement of phenylalanine by direct injection of plasma onto an internal-surface reversed-phase silica support. Clin Chem 35: $975-978$.

27. Quah BJ, Warren HS, Parish CR (2007) Monitoring lymphocyte proliferation in vitro and in vivo with the intracellular fluorescent dye carboxyfluorescein diacetate succinimidyl ester. Nat Protoc 2: 2049-2056.

28. de Alencar BC, Persechini PM, Haolla FA, de Oliveira G, Silverio JC, et al (2009) Perforin and gamma interferon expression are required for CD4+ and CD8+ T-cell-dependent protective immunity against a human parasite Trypanosoma cruzi, elicited by heterologous plasmid DNA prime-recombinant adenovirus 5 boost vaccination. Infect Immun 77: 4383-4395.

29. Geisbert TW, Bailey M, Geisbert JB, Asiedu C, Roederer M, et al. (2010) Vector choice determines immunogenicity and potency of genetic vaccines against Angola Marburg virus in nonhuman primates. J Virol 84: 10386-10394.

30. Barouch DH, Korber B (2010) HIV-1 vaccine development after STEP. Annu Rev Med 61: 153-167.

31. Corey L, McElrath MJ, Kublin JG (2009) Post-step modifications for research on HIV vaccines. AIDS 23: 3-8.

32. Martins MA, Wilson NA, Reed JS, Ahn CD, Klimentidis YC, et al. (2010) T-cel correlates of vaccine efficacy after a heterologous SIV challenge. J Virol 84 4352-4365.

33. Sekaly RP (2008) The failed HIV Merck vaccine study: a step back or launching point for future vaccine development? J Exp Med 205: 7-12.

34. McGettigan JP, Foley HD, Belyakov IM, Berzofsky JA, Pomerantz RJ, et al (2001) Rabies virus-based vectors expressing human immunodeficiency virus type 1 (HIV-1) envelope protein induce a strong, cross-reactive cytotoxic T-lymphocyte response against envelope proteins from different HIV-1 isolates. J Virol 75: 4430-4434.

35. Pancholi P, Liu Q, Tricoche N, Zhang P, Perkus ME, et al. (2000) DNA primecanarypox boost with polycistronic hepatitis $\mathrm{C}$ virus (HCV) genes generates potent immune responses to $\mathrm{HCV}$ structural and nonstructural proteins. J Infect Dis 182: 18-27.

36. Sullivan NJ, Sanchez A, Rollin PE, Yang ZY, Nabel GJ (2000) Development of a preventive vaccine for Ebola virus infection in primates. Nature 408: 605-609.

37. Curlin ME, Cassis-Ghavami F, Magaret AS, Spies GA, Duerr A, et al. (2011) Serological immunity to adenovirus serotype 5 is not associated with risk of HIV infection: a case-control study. AIDS 25: 153-158.

38. Xiang Z, Li Y, Cun A, Yang W, Ellenberg S, et al. (2006) Chimpanzee adenovirus antibodies in humans, sub-Saharan Africa. Emerg Infect Dis 12: 1596-1599.

39. Soloff AC, Liu X, Gao W, Day RD, Gambotto A, et al. (2009) Adenovirus 5- and 35-based immunotherapy enhances the strength but not breadth or quality of immunity during chronic SIV infection. Eur J Immunol 39: 2437-2449.

40. Kahl CA, Bonnell J, Hiriyanna S, Fultz M, Nyberg-Hoffman C, et al. (2010) Potent immune responses and in vitro pro-inflammatory cytokine suppression by a novel adenovirus vaccine vector based on rare human serotype 28 . Vaccine 28: 5691-5702.

41. Bayer W, Schimmer S, Hoffmann D, Dittmer U, Wildner O (2008) Evaluation of the Friend Virus model for the development of improved adenovirus-vectored anti-retroviral vaccination strategies. Vaccine 26: 716-726.

42. Gabitzsch ES, Xu Y, Yoshida LH, Balint J, Amalfitano A, et al. (2009) Nove Adenovirus type 5 vaccine platform induces cellular immunity against HIV-1 Gag, Pol, Nef despite the presence of Ad5 immunity. Vaccine 27: 6394-6398. 